
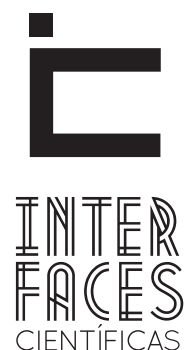

EDUCAÇÃO

ISSN IMPRESSO 2316-333X

ISSN ELETRÔNICO 2316-3828

DOI 10.17564/2316-3828.2016v4n3p69-80

\title{
A TV PÚBLICA E SEU COMPROMISSO COM A EDUCAÇ̃̃O PÚBLICA: O CASO ESCOLA 2.0
}

Siderly do Carmo Dahle Almeida ${ }^{1}$

\section{RESUMO}

Entre as invenções mais importantes do século XX, figura a televisão e a programação de sua grade de canais que vem exercendo sólida influência no cotidiano das pessoas, especialmente se for examinado seu impacto no que concerne aos aspectos da formação das atitudes, dos valores e dos comportamentos humanos. Esta pesquisa tem por intenção apresentar e analisar o Programa Escola 2.0, idealizado e produzido por uma televisão pública - a TV Cultura, da Fundação Padre Anchieta (FPA). Para poder realizar uma produção voltada para um público tão específico, a FPA conta com o Núcleo Cultura Educação, que foi criado para acompanhar os avanços tecnológicos da contemporaneidade, inte- grando mídias para produzir e disseminar conteúdos na área educacional, cuja metodologia de produção educativa em multimídias é descrita e analisada neste estudo. O Escola 2.0 é resultado de uma política de educação que visa a melhoria na qualidade do ensino e da aprendizagem dentro da escola pública. A pesquisa tem como escopo averiguar criticamente as mensagens veiculadas e foi embasada em três diretrizes, a saber: as linguagens do programa, os seus conteúdos gerais e os seus conteúdos escolares. Com o olhar nas categorias elencadas no objetivo deste trabalho, "Construção de Conhecimento" e "Aprendizagem de Valores", foram eleitas cinco subcategorias que traduzem efeti- 
vamente a preocupação com a qualidade da educação, sendo elas: "Currículo", "Tecnologia", "Integração de Saberes", "Diálogo" e "Liberdade". Nesse contexto de televisão pública comprometida com a qualidade dos temas escolares, a pesquisadora analisa os episódios apresentados na temporada 2010 do Programa.

\section{PALAVRAS-CHAVE}

Televisão Pública. Escola Pública. TV Cultura. Programa Escola 2.0. Currículo escolar.

\section{ABSTRACT}

Among the most important inventions of the twentieth century, the figure of television and his grid of channel programming has exerted solid influence on the daily lives of people, especially if their impact is examined in regard to aspects of the formation of attitudes, values and behaviors of humans. This research is intended to present and analyze the program "Escola 2.0", conceived and produced by a public television TV Cultura, of the Padre Anchieta Foundation (FPA). In order to perform a production aimed at a very specific audience, the FPA has the Education Culture Center, which was created to accompany the technological advances of today, integrating media to produce and disseminate educational content in the field, whose production methodology in educational multimedia is described and analyzed in this study. The "Escola 2.0" is the result of an education policy aimed at improving the quality of teaching and learning within the public school. The search is scoped to critically examine the messages conveyed and was based on three guidelines, namely: the languages of the program, their content and their general school subjects. With the look in the categories listed in the purpose of this study, "Building Knowledge" and "Learning Values" were elected five subcategories that translate effectively to concerns about the quality of education, namely: "Curriculum", "Technology" and "integration of Knowledge "and" Dialogue "and" Freedom. "In this context of public television compromised with the quality of school subjects, the researcher analyzes the episodes presented in the 2010 Program.

\section{KEYWORDS}

Public Television. Public School. TV Cultura. Escola 2.0 Program. School Curriculum.

\section{RESUMEN}

Entre los inventos más importantes del siglo, la figura y la televisión la programación de su parrilla de canales $X X$ ha ejercido una fuerte influencia en la vida de las personas, sobre todo si se examina su impacto en relación con los aspectos de la formación de actitudes, valores y comportamientos los seres humanos. Esta investigación tiene por objeto presentar y analizar el programa “Escuela 2.0", diseñado y producido por una televisión pública - la TV Cultura, la Fundación Padre Anchieta (APF). Para llevar a cabo una producción dentro de un público tan específico, el FPA tiene la cultura Educación Core, que fue creado para mantenerse al día con los avances tecnológicos de hoy en día, la integración de los medios para producir y difundir con- 
tenidos en el campo de la educación, la metodología de producción educativo en multimedia se describe y analiza en este estudio. La Escuela 2.0 es el resultado de una política educativa dirigida a mejorar la calidad de la enseñanza y el aprendizaje en la escuela pública. La investigación está en el ámbito de examinar críticamente los mensajes que se transmiten y se basó en tres directrices, a saber: los lenguajes de programación, los contenidos generales y sus materias escolares. Con la mirada en las categorías enumeradas en el propósito de este estudio, "Construcción del Conocimiento" y "Valores de Aprendizaje", fueron elegidos cinco subcategorías que aborden eficazmente la preocupación

\section{INTRODUÇÃo}

A vicissitude de acontecimentos e de transformações de todas as ordens sejam elas sociais, políticas ou econômicas, que permearam todo o século XX, modificando os modos de percepção e intervindo nos processos de interpretação dos signos culturais que fazem parte do cotidiano dos indivíduos, foi marca fundante em todos os patamares da sociedade. A visão determinista de mundo, até então inquebrantável, foi duramente atacada pelo influxo do indeterminismo, pelo surgimento da incerteza como nova categoria permanente, pela percepção de um novo modo de pensar e ver o mundo agora volátil, provisório, flexível. Se a visão linear traduz a racionalidade moderna, a estrutura em rede redesenha a compreensão da sociedade sob uma perspectiva pós-moderna.

Vasculhando no passado as raízes do presente, tal qual conformações que favoreçam o estabelecimento do cenário posto e esquadrinhando as leis que embasaram o sistema educacional, verifica-se que, conforme o quadro social, político e econômico do início do século XX se esboçava, a educação começava a se estabelecer como condição sine qua non para o de- por la calidad de la educación, de la siguiente manera: "Curriculum”, “Tecnología” y “Integración del Saber “y” diálogo “y la” libertad “. En este contexto, la televisión pública comprometida con la calidad de las materias de la escuela, el investigador analiza los episodios que se presentan en la temporada 2010 del programa.

\section{PALABRAS CLAVE}

Televisión Pública. Escuela Pública. TV Cultura. Programa Escuela 2.0. currículo escolar. senvolvimento do país, havendo inquietação com a instrução, nos seus diversos níveis e modalidades.

O estudo que fundamenta este artigo se dedica a apresentar o Programa Escola 2.0 produzido por uma televisão pública, de modo especial ofertado para a educação pública, com um olhar investigativo que procurou descortinar as possibilidades de construção de conhecimentos, considerando o "currículo", a "tecnologia” e a "integração de saberes”, assim como a aprendizagem de valores por meio das categorias "diálogo" e "liberdade".

O programa ora analisado é idealizado e produzido pela TV Cultura, por meio da Fundação Padre Anchieta (FPA), que tem por missão "formar cidadãos críticos para o exercício da cidadania” (MARKUN, 2010, p. 11), em que se priorize a educação e sempre se prime pela qualidade dos temas educacionais abordados em sua programação. Nesse contexto em que a televisão pública tem uma obrigação intrínseca com a educação pública, ou seja, está prescrito que a televisão pública deve contribuir com a educação pública, este traba- 
tho teve por intuito responder à seguinte pergunta: De que maneira a televisão pública consegue efetivamente contribuir para a melhoria da educação pública, considerando a produção da terceira temporada do Programa Escola 2.0, um produto bem delimitado e restrito a vinte e seis episódios de trinta minutos e que apresenta o cenário da escola, os alunos e os profissionais que nela atuam?

\section{A TV PÚBLICA E SEU COMPROMISSO COM A EDUCAÇÃO PÚBLICA: O CONTEXTO DO ESTUDO}

A televisão, essa mídia que se fundamenta em som e imagem, tornou-se um dos meios de comunicação de massa mais presente no cotidiano das pessoas e, em pleno século XXI, quando confrontada com as possibilidades que a Internet oferece, procura se adaptar às mudanças para conseguir manter seus padrões de audiência estáveis e seu público, fiel. Inventada na Inglaterra, em 1926, a TV chega ao Brasil apenas nos anos 1950, por intermédio do empresário Assis Chateaubriand.

Desde sua invenção, pode-se dizer que aquela televisão, com escassas opções de canais que acompanhou a infância e juventude de milhares de espectadores nascidos entre os anos 1950 e 1980 do século $X X$, informando, divertindo ou comovendo, cede lugar, a partir da revolução tecnológica dos últimos tempos, a uma televisão com dezenas de diferentes opções de programação. Desse ponto até o século XXI, a meta principal da televisão deixa de ser atingir toda a população, mas especialmente um determinado público que se interesse por aquela programação, afinal, vive-se em uma sociedade com audiência fragmentada marcada por distintos níveis sociais, culturais e econômicos e, assim, torna-se impossível imaginar que todos desejem assistir à mesma programação, ao mesmo tempo.

Segundo Hoineff (1996, p. 16), “a obstinação de alcançar todo o mundo representa, na verdade, o objetivo menos nobre da televisão genérica: nivelar tudo por baixo, para ter sob controle uma massa uniforme de consumidores". Ainda de acordo com esse autor, é um erro acreditar que a televisão foi pensada para criar uma massa de indivíduos acríticos, pois existe uma gama de canais que oferecem programação tão complexa quanto a própria sociedade.

A educação, por sua vez, vem tomando posição de destaque na agenda de prioridades de todos os países que se comprometeram em melhorar o padrão de vida de suas populações. Depositam-se, na conta da educação, perspectivas de que essa possa colaborar para que o desenvolvimento humano esteja em consonância com a lógica da sustentabilidade, empenhado com os preceitos da democracia.

0 próprio significado do termo "desenvolvimento" vem sendo ampliado, como distingue Sen (2000), vinculando-o à retirada das fontes principais de privação de liberdade. Tal conceito apresenta, em seu bojo, um novo enfoque permitindo abalizar de que modo os países se comportam na conquista do progresso, especialmente pela constatação da forma como as pessoas se posicionam quanto ao seu modo de vida, suas escolhas e as liberdades de que desfrutam.

\subsection{TV PÚBLICA E EDUCAÇ̃̃O PÚBLICA NO SÉCULO XXI}

Educação pública e televisão pública chegam ao século XXI e, com elas, opções de tecnologias que comportam o acesso às informações assim como ao conhecimento e a culturas distintas, favorecendo todo tipo de permuta de dados, tornando-se instrumentos imprescindíveis na origem de riquezas, no exercício do poder e na concepção de códigos culturais. Assim, tecnologia, que para Castells se traduz em uma "sociedade em rede", é conceituada como uma organização social dominante, "constituída de redes de produção, poder e experiência, que constroem a cultura da virtualidade nos fluxos globais os quais, por sua vez transcendem o tempo e o espaço" (CASTELLS, 1999, p. 427).

A economia mundial globalizada vem relacionando sujeitos e atividades em todo o mundo, assim como 
excluindo das redes de poder e de riqueza sujeitos e territórios analisados como não pertencentes sob o ponto de vista dos interesses dominantes. As redes permitem a comunicação sem fronteira espaço-temporais e integram a diversidade de culturas no que 0 autor denomina hipertexto eletrônico.

De certo modo, as transformações geram desequilíbrios, imprecisões, provocações e dúvidas, porém a revolução desencadeada pelas tecnologias de informação e comunicação suscita a urgência de outros predicados, conhecimentos, capacidades profissionais, diálogos e, em consequência disso, a educação torna-se extremamente significativa para a nova sociedade da informação, uma educação baseada em currículos que não fragmentem o conhecimento, mas, ao contrário, que possibilitem a integração de saberes. Uma sociedade que conheça seus deveres e possa bem usufruir de seus direitos. Uma sociedade que não sofra privação de liberdade.

É sobre essas categorias negritadas nesse último parágrafo, que se construiu a fundamentação teórica deste estudo.

\section{MATERIAL E MÉTODO}

Salienta-se que esta pesquisa é de natureza exploratória e de cunho explicativo, na medida, que possibilitou identificar os fatores que determinam ou contribuem para a ocorrência dos fenômenos. Neste estudo, constituíram-se fontes primárias as três temporadas do Programa Escola 2.0, exibidas em setenta e seis capítulos, veiculados pela TV Cultura. Mais precisamente, fez-se o estudo analítico da última temporada, quando oficialmente passou de "Almanaque Educação" para "Escola 2.0".

Esta pesquisa se caracteriza, ainda, pelo estudo de caso, pois se trata de um estudo empírico que investiga um "fenômeno contemporâneo dentro de seu contexto de vida real" (YIN, 2001, p. 32), que possi- bilita averiguar uma realidade, de maneira a retratar e desvendar a multiplicidade dos aspectos que permeiam determinada situação.

Neste estudo, esse procedimento se torna relevante, pois teve como foco avaliar criticamente as mensagens veiculadas pelo Programa Escola 2.0 e a sua importância para a construção de conhecimento na sociedade contemporânea, em que foram considerados especificamente, três diretrizes: as linguagens do programa, o conteúdo geral do programa e os conteúdos escolares especificamente.

A operacionalização da pesquisa contempla algumas fases específicas, as quais se expõem detalhadamente a seguir.

Em um primeiro momento, realizou-se um esquema sobre itens relevantes para dar suporte teórico ao estudo e, posteriormente, realizou-se um levantamento das obras julgadas pertinentes ao assunto.

O estudo teve por ambiente a TV Cultura. Essa fase se constituiu das seguintes etapas:

a) Pesquisa documental, que teve por intuito conhecer detalhadamente 0 ambiente de estudo. Assim, buscaram-se nos arquivos e na biblioteca da Fundação Padre Anchieta, fontes primárias que possibilitaram conhecer detalhadamente a realidade a ser estudada;

b) Seleção do caso, em que pesquisaram-se os programas editados no período de três anos (2009 a 2011) e elegeu-se um total de vinte e seis episódios, denominados Programa "Escola 2.0";

c) De posse das informações coletadas nos filmes e documentos, assim como conversas com o então diretor, Caetano Caruso; a responsável pelo conteúdo virtual, Helena Prates; a coordenadora de produção, Célia Lima; a coordenadora geral de audiovisual de educação Maria Inês Landgraf e a 
gerente de educação, Monica Gardelli Franco, tornou-se necessário eleger categorias para análise;

d) Foram selecionadas duas categorias: "Construção de Conhecimento" e "Aprendizagem de Valores". Dentre essas, elegeram-se subcategorias: "Currículo", "Tecnologia" e "Integração de Saberes" e "Diálogo" e "Liberdade";

e) Tendo como foco principal as cinco subcategorias, analisaram-se os episódios sob três diretrizes: as linguagens do programa, os conteúdos do programa e, especificamente, os conteúdos que compõem o currículo escolar, apresentados pelo programa.

Numa última etapa, tendo como "pano de fundo" o Programa Escola 2.0, teve por intuito estabelecer uma leitura das obras selecionadas promovendo um encontro de cada um desses autores e a realidade apresentada por meio da ficção nos episódios apresentados, porém considerou-se o alerta de Rudio (2000, p. 16), de que "a ciência não está interessada nas palavras em si", mas de como elas "devem servir de meios para revelar um pensamento e/ou para mostrar algo na realidade".

Para proceder à análise das categorias, propõe-se como primeira subcategoria o termo "Currículo", tendo em vista que é por meio do currículo que a escola se propõe a dar conta do que os sujeitos devem saber para que possam intervir e atuar no contexto em que vivem.

A próxima subcategoria analisada é a "Tecnologia”, permeada pelas leituras de Green (2009), Castells $(1999,2004)$ e Lévy $(1996,1999)$. A obra de Pierre Lévy se faz respeitável no contexto desta tese, tendo em vista que criou os três princípios essenciais que orientaram o crescimento inicial do ciberespaço: "a interconexão, a criação de comunidades virtuais e a inteligência coletiva” (LÉVY, 1999, p. 127).

Ao analisar a subcategoria "Integração de saberes", buscou-se a verificação das obras de Morin (2005), (2007) e Delors (1998). A leitura de tais obras leva a uma revisão das práticas pedagógicas, fazendo pensar sobre os desafios e incertezas enfrentados na contemporaneidade, contemplando a todos aqueles que se preocupam com o futuro da humanidade.

Paulo Freire $(1985,1987,1999,2001,2007)$ foi fundamental para a análise da categoria "Aprendizagem de Valores”, subcategoria “Diálogo.

O diálogo é uma profunda compreensão da alteridade, da valorização do ser humano. É por meio do diálogo entre os pares que se descobrem as oportunidades para se desenvolverem os mais variados saberes. Finalmente, à escola, compete a função de proporcionar que o ser humano recupere a visão do todo e possa viver como cidadão do mundo que é, recuperando o equilíbrio entre razão e emoção, alcançando a condição de escrever sua história no mundo.

A última subcategoria considerada é "Liberdade" e, para analisá-la, emprestou-se o olhar de Amartya Sen (2000). São inúmeras as dificuldades que assolam o mundo de modo geral: a extrema pobreza, a fome, a marginalização social, a ausência de oportunidades, a exploração, enfim, a insegurança econômica, politica e social. Para Sen, o desenvolvimento é fundamentalmente um processo de expansão das liberdades e, apenas desse modo, é possível restaurar a dimensão ética e política dos problemas econômicos enfrentados pela população.

Cada uma dessas subcategorias será analisada a partir de três diretrizes que são:

a) As linguagens do programa, tendo em vista os detalhes da tessitura dos episódios, que, segundo Fischer (2001, p. 104), envolvem "recursos audiovisuais, de imagem, som, textos, edição, a escolha de planos e ritmos, a seleção de apresentadores e atrizes", ou seja, a fotografia, os diálogos, os cenários, os personagens, a forma como o programa é editado, as vinhetas de abertura e de passagem de um tema a outro; 
b) Os conteúdos do programa, considerando os temas acerca do que se discute, de que modo essas discussões são apresentadas, quais os comportamentos e atitudes exibidos, e, se existem situações de conflito, tal como na "vida real”, como essas são expostas. A esse viés não importa especificamente o alcance educacional, embora possa enriquecer o currículo ao se observar uma formação mais ampla que busca desenvolver a sensibilidade, o imaginário, a criatividade;

c) Os conteúdos que compõem o currículo escolar. Nesse caso, não há uma finalidade instrucional específica, porém os conteúdos abrangem temas que deveriam integrar a bagagem cultural básica do público-alvo. Para Fischer (2001, p. 132), “são temas históricos (antigos ou recentes) científicos (de todos os campos: natureza, vida, biologia, física, sociologia, economia, medicina, psicologia), socioculturais e políticos, artísticos”. Esses temas podem desempenhar funções pedagógicas relevantes, tais como "motivar, contextualizar, aprofundar, diversificar pontos de vista, questionar e discutir, auxiliar a compreensão de processos e conceitos" (FISCHER, 2001, p. 133).

É dentro do contexto: de escola enquanto instituição na sociedade responsável pela educação, de televisão pública comprometida com a qualidade dos temas educacionais e escolares que apresenta e com o olhar preciso nas três diretrizes dessas cinco subcategorias, que a pesquisadora analisa os episódios apresentados na última temporada do Escola 2.0.

\section{PROGRAMA ESCOLA 2.0:DIRETRIZES ANALISADAS NESTE ESTUDO}

Assistiu-se a cada um dos vinte e seis episódios da terceira temporada do programa, primeiramente de um modo mais superficial, apenas como uma telespectadora em busca de entretenimento. Num segundo momento, houve um aprofundamento buscando-se vislumbrar se e de que modo as categorias pensadas eram apresentadas no programa, e ainda, sob quais aspectos poderiam ser analisadas.

\subsection{AS LINGUAGENS DO PROGRAMA}

A primeira diretriz analisada neste estudo, "as linguagens do programa”, foi escolhida porque, antes de conhecer o conteúdo de um programa, o telespectador é fisgado pelas imagens que apresenta, pelos sons, pelas formas e cores oferecidas. Segundo Fischer (2001, p. 114),

\begin{abstract}
A leitura audiovisual mais qualificada expande a capacidade de compreender, distinguindo e ao mesmo tempo integrando substâncias e formas. Apura a percepção visual e auditiva, permitindo identificar e apreciar a composição imagem/som/texto, que é a própria essência dessa linguagem e fonte de sua atração.
\end{abstract}

Essa linguagem que se fundamenta na mixagem de imagens, sons, cores, formas e palavras são captadas pelos sentidos, e só então são refinadas, compreendidas, interpretadas, transformando-se possivelmente em emoções.

Visto por esse aspecto, o programa cumpre efetivamente com seu objetivo, pois se observa uma linguagem que se vale de um ritmo acelerado bem ao gosto dos adolescentes que estão sempre inquietos e antenados com as tecnologias, conectados a várias atividades ao mesmo tempo como uma mensagem no celular, uma publicação no facebook, uma "twittada", uma partida de um novo game e um videoclipe no youtube. Além disso, mistura animações a cenas do dia a dia, acrescentando um "tempero" diferente dos propostos pelas novelas assistidas por um público mais maduro, numa abordagem mais leve e bem-humorada. A edição do programa prima pela edição ágil e a linguagem lúdica associadas à disseminação de muita informação.

O currículo se faz presente ao elencar elementos da cotidianidade dos adolescentes vinculados ao es- 
paço da escola, completando-se tal viés, pois, analogamente, é neste local que o público alvo se defronta com suas angústias, suas alegrias, suas emoções, assim, sentem-se em casa, assistindo na telinha aquilo que vivem na "vida real".

Percebe-se a preocupação com a integração de saberes quando o programa busca combinar em seus quadros: sentidos, significados, histórias, contextos, entrevistas, que contribuem para que os jovens telespectadores possam formar suas próprias considerações sobre os temas apresentados. Um mesmo saber é apresentado por diferentes ângulos e em variadas linguagens.

Os diálogos são curtos e diretos, promovendo maior facilidade de compreensão, considerando-se que este público é mais imediatista. Permite-se ainda um diálogo mais próximo com os telespectadores ao se considerar a possibilidade de que estes façam suas contribuições, teçam elogios, estabeleçam críticas, por meio dos blogs dos personagens.

Ao relacionar essa diretriz à questão da liberdade percebe-se que houve uma preocupação não só em situar a importância da liberdade de expressão entre os protagonistas do programa, como também em possibilitar que seu público pudesse ter tal liberdade, utilizando como meio para isso, os blogs "Barulho da Bia” e "Almanaque Educação". Isso pode ser avaliado tendo em vista o número de visitas e de participações em ambos, verificando que os jovens os acessam para apresentar dúvidas, sugestões e reflexões acerca de cada episódio e da trama como um todo.

\subsection{CONTEÚDOS DO PROGRAMA}

A segunda diretriz eleita, foi a de conteúdos do programa de um modo geral, pois, após gostar do que se vê e do que se ouve, o público se prende pelo conteúdo apresentado. Nessa análise, não se buscaram conteúdos que pertencessem ao currículo, mas que, de algum modo, enriquecessem a formação dos adolescentes. Fischer (2001, p. 101) ressalta que:
[...] quando o estudo da televisão se torna uma prática frequente no espaço escolar - em qualquer nível -, é possível que professores e alunos se deem conta de como assumem relevância certos temas na sociedade, na medida em que se tornam públicos, debatidos nesse espaço amplo da televisão.

Há que se salientar que por meio dessa diretriz e, considerando a primeira subcategoria analisada, o currículo, o programa cumpre com seu objetivo, pois procura oferecer conteúdos que buscam envolver os contextos nos quais os alunos estão inseridos. Segundo Apple, esse é um conceito fundamental na composição de um currículo. 0 autor ressalta, ainda, que os conteúdos não podem ser valorizados como um fim em si mesmo, assim como a intenção de construir o conhecimento sistematizado na escola deve estar densamente relacionada com a possibilidade de permitir aos educandos uma maior apreensão da realidade na qual estão inseridos.

A questão das tecnologias foi fartamente trabalhada no programa. Especificamente nesse viés dos conteúdos, a produção demonstrou inúmeras possibilidades que ela oferece em todos os aspectos da vida cotidiana, seja para localizar pessoas desaparecidas, para estabelecer contatos, aprender coisas novas, expor ideias, encontrar soluções para o dia a dia, demonstrar sentimentos. 0 trio se utiliza de todos esses instrumentos com o intuito de viabilizar a produção de seus blogs "Almanaque" e "Barulho da Bia” e, por meio desses, se expressam, enunciam conceitos, questionam, criticam, enfim, discutiem questões que levam à reflexão a respeito da liberdade e da privacidade que a tecnologia promove, tal qual exposto pelos teóricos neste estudo.

A integração de saberes pode ser observada em vários episódios apresentados, atendo-se principalmente ao trio de protagonistas que buscam aliar seus conhecimentos para ajudar a solucionar os problemas de outros personagens e até deles mesmo. Isso pode ser visto claramente no episódio “Marginalidade”, que apresenta Cadu, Mano e Bia unidos para ajudar o ami- 
go Tonhão, ao verificar que esse enfrenta problemas, ausentando-se até dos treinos de basquete, o que gosta de fazer. 0 trio propõe um modo de ajudá-lo a resolver seus conflitos. Em outro programa, os protagonistas colaboram com o professor Lívio que está com dificuldades em harmonizar sua vida pessoal com a professional.

Percebe-se constantemente a busca pelo respeito às opiniões e conceitos de cada um, por meio dos diálogos travados. Tal qual no "mundo real”, o trio Cadu, Mano e Bia - muitas vezes se depara com opiniões díspares sobre diversos assuntos e, ao final de cada edição, as situações tendem a se resolver. Com isso, denota-se a importância de haver divergência de opiniões, pois é nesse confronto que surgem novas ideias, novos conceitos, novas reflexões e é aí que o conhecimento se constrói.

Muitos conteúdos apresentados nos episódios relacionam-se diretamente à liberdade nas categorias apresentadas por Sen. Evidenciou-se principalmente a questão das "facilidades econômicas, as garantias de transparência, a segurança protetora e, de forma especial, a liberdade individual como um comprometimento social" (SEN, 2000, p. 320), em que o autor explicita que as pessoas têm a obrigação e a responsabilidade de desenvolver e aprimorar o mundo em que vivem. Com isso torna-se imprescindível contribuir para minimizar os problemas que afligem o outro e, desse modo, colaboração é essencial. No programa Escola 2.0, observa-se nitidamente a busca por contribuir no sentido de melhorar a vida do outro e, consequentemente, da sociedade.

\subsection{CONTEÚDOS QUE COMPÕEM O CURRÍCULO ESCOLAR}

A terceira e última diretriz analisada relaciona-se aos conteúdos que compõem o currículo escolar, considerando não uma finalidade de instrução, porém a busca por temas que possam integrar esse currículo, meIhorando a bagagem cultural e de conhecimento do telespectador. De acordo com Gimeno Sacristán (1998, p. 154),
Muitos conteúdos, não estritamente acadêmicos, não correspondem a nenhuma especialização curricular ou disciplina, enquanto que outros estão relacionados com todas. Em muitos casos se referem a processos educativos ligados ao ensino de conhecimentos a serem assimilados (a cultura como produto). Em outros, exigem o estímulo de atitudes, hábitos de comportamento e habilidades que só são obtidas depois de experiências continuadas, que dependem estreitamente do tipo de processos de aprendizagem que se desenvolvem e das condições em que estas acontecem (referência à cultura como processo).

Sob essa ótica de que o conhecimento se constrói tanto por meio da cultura enquanto produto quanto da cultura como processo, que avalia que os conteúdos que compõem o currículo distinguem-se como processo social e pedagógico e, principalmente, que considera a experiência de aprendizagem como conteúdo curricular, pode-se afirmar que, por esse terceiro viés, ao se analisarem as cinco subcategorias elencadas, o programa Escola 2.0 atinge seu objetivo.

A tecnologia é intrinseca ao programa analisado. Em todos os episódios, ela se faz presente. Sugere-se, a todo tempo, maneiras de utilizá-la em vários sentidos, propondo que se pode construir conhecimento, tirando proveito das mais variadas probabilidades que oferece. A pesquisa, a autoaprendizagem, as conexões que se estabelecem, sem dúvida, as tecnologias auxiliam na criação de ambientes ricos em possibilidades de aprendizagem, em que os interessados e motivados podem adquirir quase qualquer conhecimento sem precisar entrar em um processo formal de ensino.

A integração de saberes foi enfaticamente abordada, sugerindo inclusive formas de trabalhar um mesmo tema em diversas disciplinas que compõem o currículo escolar.

Sob o olhar dos conteúdos escolares, percebe-se que o diálogo está presente em todos os episódios, apresentando alunos conectados ao mundo e ao seu tempo, partilhando opiniões, debatendo conceitos, ressaltando tendências, ponderando ideias, enfim, construindo conhecimentos. 
Com relação à liberdade, pode-se afirmar que, em diversos episódios, tal tema é apresentado, abalizando o quanto o seu debate é importante no currículo escolar. Um dos principais pontos constantemente levantados é a questão da ética (um dos temas transversais propostos pelos Parâmetros Curriculares Nacionais), demonstrando-se a importância da solidariedade, do respeito as opiniões, da justiça, de modo geral.

\section{CONSIDERACÕ̃ES FINAIS}

Este estudo teve por propósito mergulhar em dois universos distintos, cujos contextos se circunscrevem em torno de questões concebidas nas relações que se estabelecem entre as pessoas nos diversos segmentos da sociedade: a televisão pública e a escola pública, por meio do olhar de um programa de televisão que é o Escola 2.0, idealizado e produzido pela TV Cultura.

Ver televisão parece algo muito despretensioso, ou seja, além do tempo, não exige nada de ninguém, porém, as pessoas envolvidas com a elaboração de um programa sabem quais os objetivos que pretendem atingir junto ao seu público, seja ele qual for. Portanto, de caráter despretensioso, ou ainda de neutro, os programas não têm nada.

Neutra também não é a educação que estreita laços com as políticas públicas para atingir seu objetivo de permitir às novas gerações o acesso ao mundo do saber sistematizado, possibilitando que o aluno tenha atitude reflexiva, curiosidade científica, hábito de análise e de crítica diante de um conhecimento e, com isso, possa melhorar suas chances de sucesso na economia do mundo contemporâneo, como uma questão de sustentação de seu crescimento e o de outros, tanto quanto uma questão de justiça e inclusão, em que as oportunidades sejam disponibilizadas a todas as raças, origens e aptidões iniciais.

A televisão pública nasceu com o propósito de melhorar a qualidade da educação brasileira; por conseguinte, tem um compromisso estabelecido com a escola pública. Assim, a TV Cultura criou o Núcleo Cultura Educação que comporta educadores, pedagogos, comunicólogos e sociólogos que trabalham em prol de idealizar e produzir programas que possam atingir tal objetivo.

o Escola 2.0 é, pois, fruto deste trabalho colaborativo, uma vez que cada episódio apresentado demonstra preocupação em alinhar escola, aluno, família e sociedade, enfatizando que a escola é uma instância de socialização que tem a missão de preparar os jovens para uma vida em coletividade. É nesse espaço que os alunos entram em contato com a tradição, apresentada no Escola 2.0 por meio de seus vários quadros, como por exemplo, em "Trabalho coletivo" quando no quadro Pílulas de sabedoria, explica-se o significado do termo "um minuto de silêncio".

Também à escola é atribuída a função de socializar valores e saberes. Nesse aspecto, apenas para citar um exemplo, o Escola 2.0 apresentou no quadro "Fala aî" do episódio "Acusação" o que é cyberbullying, questionando aos adolescentes de que modo isso acontece e como poderia ser evitado. Um último aspecto a se evidenciar é que a escola sustenta-se na arte de ensinar a todos indistintamente, precisando estar atenta às necessidades e instabilidades psicológicas de cada um dos educandos que despontam como sujeitos em uma sociedade complexa. Nesse aspecto, o programa demonstra em vários episódios a preocupação em tornar a vida de todos o mais harmônica possível. Isso é notado tanto entre os três protagonistas como com relação ao grupo docente e aos demais alunos que compõem o programa.

Assim, com esses dados analisados, considera-se que um programa dessa natureza, do modo como foi idealizado, concebido e produzido é capaz de trazer uma contribuição efetiva à educação. 0 desenho e a lógica propostos pelo Núcleo Cultura Educação da TV Cultura para o Programa Escola 2.0, contemplam aspectos primordiais levantados neste estudo, re- 
velando um compromisso com as políticas públicas para que se consolide uma educação de qualidade, podendo se tornar um indicador para produção de programas educativos.

\section{REFERÊNCIAS}

ALMEIDA, Fernando José de. Folha explica Paulo Freire. São Paulo: Publifolha, 2009.

BARDIN, Laurence. Análise de conteúdo. Lisboa: 70, 2000.

BOURDIEU, Pierre. Sobre a televisão: seguido de, A influência do jornalismo; e, Os Jogos Olímpicos. Rio de Janeiro: J. Zahar, 1997.

CASTELLS, Manuel. Sociedade em rede. São Paulo: Paz e Terra, 1999.

FISCHER, Rosa Maria Bueno. Televisão \& educação: fruir e pensar a TV. 2.ed. Belo Horizonte: Autêntica, 2001.

GIL, Antonio Carlos. Métodos e técnicas de pesquisa social. 5.ed. São Paulo: Atlas,1999.

GIMENO SACRISTÁN, J. O currículo: os conteúdos do ensino ou uma análise prática. In: GIMENO
SACRISTÁN, J.; PÉREZ GÓMEZ, A. I. Compreender e transformar o ensino. 4.ed. Porto Alegre: ArtMed, 1998.

HOINEFF, Nelson. A nova televisão: desmassificação e o impasse das grandes redes. Rio de Janeiro: Relume Dumará, 1996.

LÉVY, Pierre. Cibercultura. São Paulo: 34, 1999.

MARKUN, Paulo. Educação para um país mais justo e eficiente. In: ALMEIDA, Fernando José de. Cultura é educação. São Paulo: Fundação Padre Anchieta, 2010.

MORIN, Edgar. Os sete saberes necessários à educação do futuro. 10.ed. São Paulo: Cortez, 2003.

OLIVEIRA, M. M. Como fazer pesquisa qualitativa. Petrópolis: Vozes, 2007.

RUDIO, Franz Victor. Introdução ao projeto de pesquisa científica. 27.ed. Petrópolis: Vozes, 2000.

SEN, Amartya Kumar. Desenvolvimento como

liberdade. São Paulo: Companhia das Letras, 2000.

YIN, R. K. Estudo de caso: planejamento e métodos. 2.ed. Porto Alegre: Bookman, 2001. 
